\title{
É PRECISO TER CAUTELA E TRANSPARÊNCIA PARA DEBATER A REFORMA DA PREVIDÊNCIA
}

Coluna publicada em 2.5.2017: <https://www.conjur.com.br/2017-mai-02/ contas-vista-preciso-transparencia-debater-reforma-previdencia $>$

Há algumas questões que parecem nunca sair da pauta de reformas constitucionais e legislativas, como a reforma "tributária"1 e a do sistema previdenciário.

Nos últimos meses a chamada "reforma previdenciária" tem ocupado a atenção do Congresso Nacional, que colocou importantes medidas a ela relacionadas em pauta de votação, como a PEC 287/2016. O debate sobre o tema está na mídia e nas ruas, como se viu nas manifestaçôes ocorridas em 28 de abril de 2017.

É interessante notar como um tema de tamanha relevância para a vida das pessoas e do país é tão pouco estudado, sendo escassos os trabalhos que abordam o tema com profundidade - embora isso não venha a ser novidade no âmbito do Direito Financeiro, em que fatos como esse chegam a ser corriqueiros.

Uma falha que os estudiosos não podem continuar a cometer, e o momento é mais do que oportuno para se dedicarem ao tema e suprirem esta inexplicável lacuna, trazendo elementos que possam esclarecer a todos, qualificar o debate, $\mathrm{e}$ não deixar que se cometam erros em um assunto que afeta as gerações presente e futura.

Para isso é importante que se conheçam algumas informações básicas que formam a estrutura jurídico-financeira do sistema previdenciário brasileiro.

De início, há que se destacar ser de tal forma relevante esse sistema, que a lei orçamentária anual dos entes da federação brasileira, nos expressos termos do art.

1 Que prefiro colocar entre aspas porque defendo que as principais questôes controvertidas estão muito mais no âmbito do direito financeiro do que tributário, sendo mais correto se a denominassem de "reforma financeira". 
165 da Constituição, comporta uma subdivisão em três partes, a saber: a) o orçamento fiscal, referente aos Poderes do ente federado, seus fundos, órgãos e entidades da administração direta e indireta, inclusive fundações instituídas e mantidas pelo poder público; b) o orçamento de investimento das empresas controladas pelo o ente da federação; e c) o orçamento da seguridade social, que abrange "todas as entidades e órgãos a ela vinculados, da administração direta ou indireta, bem como os fundos e fundações instituídos e mantidos pelo poder público”.

Uma organização orçamentária que se mostra de todo conveniente, pois permite melhor administração, maior controle e transparência sobre os recursos da seguridade social, evitando que se dispersem por todo o orçamento, misturando receitas e despesas de diversas naturezas e impedindo que se conheça a estrutura financeira do que está entre os mais - senão o mais - importante sistema de proteção financeira dos direitos sociais.

Há que se destacar a relevância financeira do orçamento da Seguridade Social, que, neste exercício financeiro de 2017 , segundo a lei orçamentária federal vigente (Lei 13.414/2017), estima a receita total da União em mais de três trilhões de reais ( $\$$ \$ 3.505.458.268.409,00), e o orçamento da Seguridade Social participa nesse montante com mais de seiscentos bilhões de reais ( $\mathrm{R} \$$ 668.099.666.174,00).

Desde logo convém observar que previdência social, cuja reforma está em acalorada discussão, insere-se no contexto da seguridade social, que abrange saúde, assistência social e a previdência social. A Constituição trata do tema nos artigos 194 a 204 (Saúde, arts. 196 a 200; Previdência Social, arts. 201 e 202; e Assistência Social, arts. 203 e 204).

O art. 195 prevê que a seguridade social será financiada por toda a sociedade, sendo fontes de receita da seguridade social (e não somente da previdência social), recursos dos orçamentos de todos os entes federados e também (mas não somente) ${ }^{2}$ das seguintes contribuições sociais:

"I - do empregador, da empresa e da entidade a ela equiparada na forma da lei, incidentes sobre:

a) a folha de salários e demais rendimentos do trabalho pagos ou creditados, a qualquer título, à pessoa física que lhe preste serviço, mesmo sem vínculo empregatício;

2 O art. 11 da Lei 8.212/1991 também é claro nesse sentido, ao dispor que, no âmbito federal, o orçamento da Seguridade Social é composto por receitas da União, das contribuiç̧̃es sociais e de outras fontes. 
b) a receita ou o faturamento;

c) o lucro;

II - do trabalhador e dos demais segurados da previdência social, não incidindo contribuição sobre aposentadoria e pensão concedidas pelo regime geral de previdência social de que trata o art. 201;

III - sobre a receita de concursos de prognósticos.

IV - do importador de bens ou serviços do exterior, ou de quem a lei a ele equiparar."

A Lei 8.212/1991 detalha o financiamento da seguridade social (arts. 10 e seguintes), enumerando as diversas formas de obtenção de recursos especificamente destinados a compor o orçamento da Seguridade Social, evidenciando, apenas no que tange a este aspecto, uma ampla gama de fontes que entram na composição das receitas do sistema.

Incomparavelmente mais complexa é a especificação do que deve ser incluído como despesa da seguridade social como um todo, incluindo a previdência social. Inúmeros exemplos poderiam ser citados evidenciando a dificuldade em delimitar quais sejam essas despesas, e também separar benefícios previdenciários de assistenciais. Em razão disso, o fato é que se constata não ser simples a verificação do desejável equilíbrio entre as receitas e despesas do sistema de previdência social, e apuração do eventual déficit existente, a fim de que seja possível, com segurança e transparência, promover alteraçóes que efetivamente tragam uma solução para o problema, no curto e longo prazos, garantindo a sustentabilidade do sistema.

A esse já difícil detalhamento das receitas e despesas que compõem o sistema de previdência social, soma-se o "desenvolvimento e aprimoramento" da "contabilidade criativa", que "evoluiu" muito nos últimos anos, e pouca segurança se consegue ter do que deve ou não estar no rol dos itens que a integram. Muitas das despesas alocadas no orçamento da Seguridade Social são de discutível relação com suas finalidades, onerando-o indevidamente. ${ }^{3}$

Recentemente, mudanças na organização da administração pública federal intensificaram ainda mais a dificuldade no gerenciamento dos recursos da previdência social. O Ministério da Previdência Social, que concentrava a administração do sistema, já no governo da ex-presidente Dilma Rousseff, foi incorporado ao Ministério do Trabalho e, mais recentemente, no atual governo, ao Ministério da

3 Nesse sentido, veja-se CALCIOLARI, Ricardo. O orçamento da Seguridade Social e a efetividade dos direitos sociais. Curitiba: Juruá, 2009. p. 135-136, entre outros trechos. 
Fazenda. De fato, tornaram-se ligados ao Ministério da Fazenda o Conselho Nacional de Previdência e a Empresa de Tecnologia e Informações da Previdência (antes denominados Conselho Nacional de Previdência Social e Dataprev, respectivamente). Da mesma forma a Superintendência Nacional de Previdência Complementar (Previc), o Conselho Nacional de Previdência Complementar e a Câmara de Recursos da Previdência Complementar. O Instituto Nacional do Seguro Social (INSS) e o Conselho de Recursos da Previdência Social passaram a compor, no entanto, o Ministério do Desenvolvimento Social e Agrário - mudança que parece ter surpreendido até o ministro da pasta. ${ }^{4}$ Com isto, este Ministério é o órgão atualmente responsável pelo Programa 2061 (Previdência Social), o qual, no orçamento de 2016, situava-se no âmbito de competências do Ministério do Trabalho e Previdência Social. ${ }^{5}$

Com isso, os recursos relacionados à previdência social, sob o aspecto da classificação orçamentária institucional, ficaram bastante dispersos, dificultando a visualização, identificação e gerenciamento da atividade financeira relacionada à previdência social.

Não se pode esquecer também da DRU - Desvinculação de Receitas da União, que permite a desvinculação, até o final de 2023 , de $30 \%$ da arrecadação da União em relação às contribuições sociais, contribuições de intervenção no domínio econômico e taxas. A desvinculação foi estendida ainda aos Estados (art. 76-A do ADCT) e aos Municípios (art. 76-B), com as exceções ali elencadas. A este respeito, nota-se que desde o surgimento do Fundo Social de Emergência, fruto da Emenda Constitucional de Revisão n 1, de 1994, desafeta-se parte das receitas das contribuições sociais já referidas, destinadas a financiar a seguridade social. Esta previsão reiterou-se, ainda, no Fundo de Estabilização Fiscal (ECs 10/1996 e 17/1997) e nas regras anteriores da DRU, pelas Emendas 27/2000, 42/2003, 56/2007 e 68/2011, até chegar à forma atualmente vigente.

Excessos de renúncias fiscais, elevada sonegação de tributos e contribuições, e leniência na cobrança da dívida ativa, só agravam o quadro de incerteza sobre qual é a verdadeira situação das finanças públicas em matéria previdenciária, e dificultam aferir a existência e exata dimensão do alegado déficit, bem como suas reais causas.

4 <http://politica.estadao.com.br/blogs/coluna-do-estadao/inss-vai-para-desenvolvimento-social-e-agrario-e-ate-ministro-fica-surpreso-com-mudanca/>.

5 Ver, a propósito, a Lei 13.414 , de 10 de janeiro de 2017, que estabelece o orçamento para o exercício de 2017, em conjunto com a Lei 13.341, de 29 de setembro de 2016. 
Em face de tudo o que se pode constatar, vê-se que o orçamento da Seguridade Social, como instrumento para dar transparência, garantir o equilíbrio financeiro e aperfeiçoar a gestão do sistema de seguridade social, e por consequência da previdência social, está com suas funções bastante prejudicadas, como destacou Élida Graziane Pinto neste espaço. ${ }^{6}$

Do exposto, não é de se espantar a diversidade de opiniões sobre o tema, com posiçôes diametralmente opostas, e todas elas fundadas em dados financeiros e estatísticos, o que deixa atônitos não só o cidadão comum, como também os parlamentares que estão com a responsabilidade de decidir esse tema crucial para o presente e o futuro do país.

Há uma quase unanimidade em reconhecer existir uma insustentabilidade do sistema previdenciário no longo prazo, o que exigiria uma reforma o quanto antes para evitar este problema futuro, e nesse sentido é de se louvar a firme atuação dos governantes. Um raro exemplo de preocupação com as próximas gerações, o que é bastante inusitado, verdadeira exceção à regra infelizmente vigente, de pensar somente no presente e agir como bombeiro, apagando incêndios e consertando erros cometidos no passado. Mas a questão é por demais relevante e há que se agir com cautela.

Esse espaço é por demais exíguo para discorrer sobre o tema com um mínimo de profundidade. Há ainda a tormentosa questão da previdência dos servidores públicos e a situação dos Estados e Municípios. Mas penso ser importante chamar a atenção para a enorme complexidade e dimensão do problema. E a evidente necessidade de que sejam feitos estudos mais claros, transparentes e compreensíveis, que permitam tomar decisões acertadas. A sociedade tem pressa, as reformas urgem, e o tempo está passando. Mas o provérbio "a pressa é inimiga da perfeição" aplica-se com perfeição (com o perdão pela redundância) a essa situação. E a sabedoria popular manda nesses casos andar "devagar com o andor, que o santo é de barro".

Os trabalhadores, que ontem comemoraram o seu dia, e são os responsáveis pela construção de um país melhor, merecem ter seus direitos respeitados e a segurança de um sistema justo que os proteja na saúde, doença e velhice, e para isso é preciso que se construa e mantenha um bem estruturado sistema de previdência social, o que não se faz sem estudos profundos, sérios e tecnicamente precisos, que devem ser analisados com cuidado e sem açodamento.

6 Inconstitucionalização do réquiem para o orçamento da Seguridade Social, publicada em 28 de março de 2017 no ConJur. 
